\title{
The Best reviewers of International Brazilian Journal of Urology in 2020
}

\author{
Luciano A. Favorito ${ }^{1,2}$
}

${ }^{1}$ Unidade de Pesquisa Urogenital - Universidade do Estado de Rio de Janeiro - Uerj, Rio de Janeiro, RJ, Brasil, ${ }^{2}$ Serviço de Urologia, Hospital Federal da Lagoa, Rio de Janeiro, RJ, Brasil

\section{COMMENT}

The peer review system is the soul of the Scientific journals. This process became an institutionalized part of the scholarly process in the latter half of the twentieth century (1). The serious review process is done by experts on the topic studied and is completely free depending on the goodwill and talent of the reviewers. The process of peer review is hard but improve the quality of published scientific manuscripts (2).

In 2020 the International Brazilian Journal of Urology received more than 900 papers and the reviewers were very important to the entire process of our Journal. As a Editor-in-Chief I would like to thanks all the reviewers and specially the Doctors: Alexandre Danilovic, MD (Hospital das Clínicas da Faculdade de Medicina da USP); Ralf Anding, MD (University Hospital Basel); John Denstedt, MD, PhD (Western University Canada); Trushar Patel, MD (University of South Florida) and Gustavo Ruschi Bechara, MD (Hospital Universitário Cassiano Antônio Moraes) who reviewed more than 5 articles during the year and strictly within the deadline.

Thanks a lot!!!!!

Luciano A. Favorito

Editor-in-Chief

International Brazilian Journal of Urology 


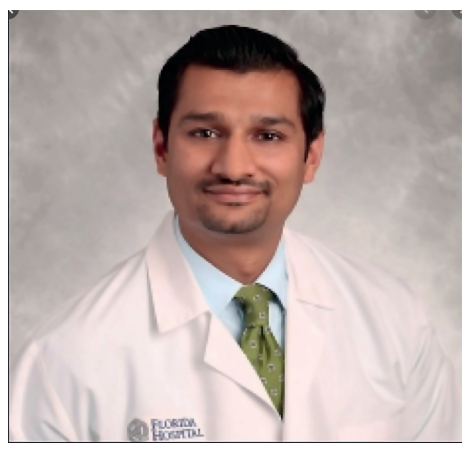

Trushar Patel, MD

University of South Florida

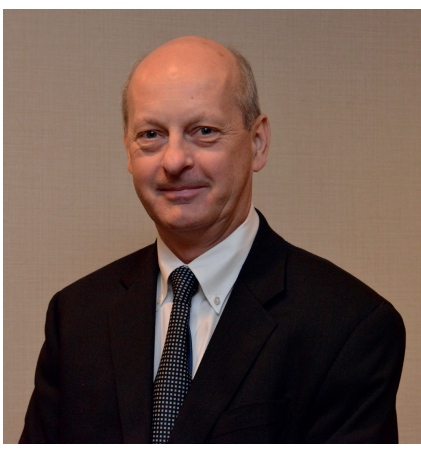

John Denstedt, MD, PhD

Western University Canad

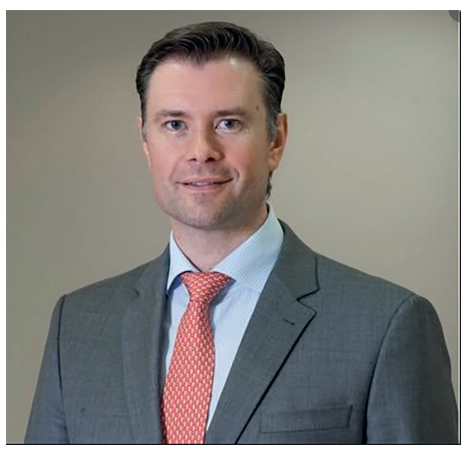

Alexandre Danilovic, MD Hospital das Clínicas da Faculdade de Medicina da USP

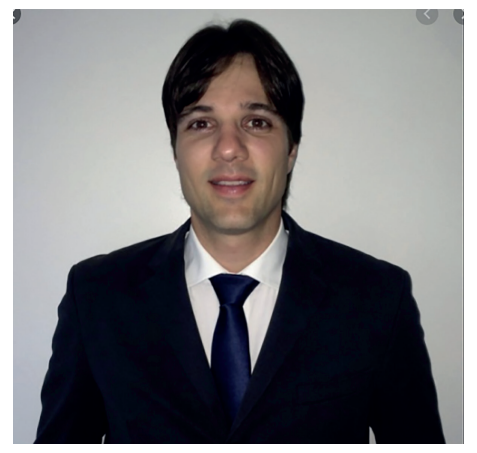

Gustavo Ruschi Bechara, MD, PhD

Hospital Universitário Cassiano Antônio Moraes

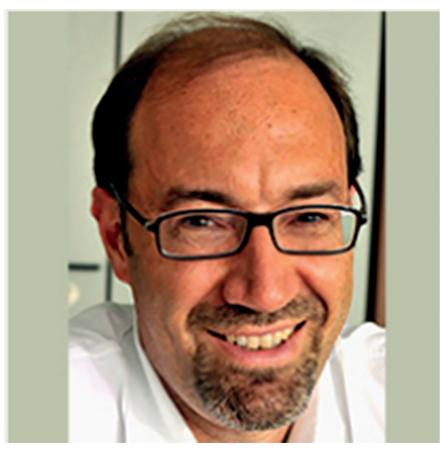

Ralf Anding, MD

University Hospital Basel

\section{REFERENCES}

Luciano A. Favorito, MD, PhD

1. Manchikanti L, Kaye AD, Boswell MV, Hirsch JA. Medical journal peer review: process and bias. Pain Physician. 2015;18:E1-E14.

2. Margalida A, Colomer MÀ. Improving the peer-review process and editorial quality: key errors escaping the review and editorial process in top scientific journals. PeerJ. 2016;4:e1670.

ARTICLE INFO

Luciano A. Favorito http://orcid.org/0000-0003-1562-6068

Int Braz J Urol. 2021; 47: 4-5 